\title{
CHARACTERIZATION OF LIPOPHILIC WOOD EXTRACTIVES FROM CLONES OF Eucalyptus urograndis CULTIVATE IN BRAZIL
}

\author{
Flaviano O. Silvério ${ }^{\mathrm{a}, \mathrm{b}}$, Luiz C. A. Barbosa ${ }^{\mathrm{a}^{*}}$, Célia R. A. Maltha ${ }^{\mathrm{a}}$, Armando J. D. \\ Silvestre $^{\mathrm{c}}$, Dorila Pilo-Veloso ${ }^{\mathrm{b}}$ and José L. Gomide ${ }^{\mathrm{d}}$,
}

\begin{abstract}
The chemical compositions of the lipophilic extractives from four clones of Eucalyptus urograndis cultivated in Brazil were studied by gas chromatography-mass spectrometry (GC-MS) before and after alkaline hydrolysis. The four $E$. urograndis clones showed similar amounts of dichloromethane soluble (lipophilic) extractives $(0.38-0.55 \% \mathrm{w} / \mathrm{w})$. The major groups of compounds identified in the lipophilic fraction of extractives consisted mainly of fatty acids (mainly palmitic linoleic and oleic acids and small amounts of $\alpha$ - and $\omega$-hydroxyacids), steroids (mainly $\beta$-sitosterol, $\beta$-sitostanol), followed by minor amounts long chain aliphatic alcohols, hydrocarbons and aromatic compounds. The relative abundances of these groups were similar for three of the clones with exception of the clone Ugc, which was shown to have much higher amounts of fatty acids and sterols. The high amounts of extractives found in these clones, and particularly of Ugc, when compared with other Eucalyptus species, suggests an increased risk of pitch formation during bleached pulp production.
\end{abstract}

Keywords: Lipophilic extractives, E. urograndis, Pitch, GC-MS analysis, Fatty acids, Steroid.

Contact information: a: Department of Chemistry, Federal University of Viçosa, 36570-000, Viçosa, Brazil; b: Department of Chemistry, Federal University of Minas Gerais, 31270-901, Belo Horizonte, Brazil; c: CICECO and Department of Chemistry, University of Aveiro, 3810, Aveiro, Portugal; d: Department of Forest Engineering, Federal University of Viçosa, 36570-000, Viçosa, Brazil; *Corresponding author: lcab@ufv.br

\section{INTRODUCTION}

Eucalyptus wood is at the present the most important short fiber source for pulp and paper production in Brazil due to its rapid growth and abundance throughout the country (Shatalov et al. 1999), as well as to its excellent pulp properties (Back and Allen 2000; Hillman 2002). Interest in the use of Eucalyptus species for pulp production has furthered research related to the chemical composition of this type of wood, aiming to improve the quality of clone plantations by means of genetic selection, considering especially the wood bulk chemical characteristics and the physico-mechanical properties of the ensuing bleached kraft fibres (Gonçalves et al. 2001; Caixeta et al. 2003a, 2003b).

In the last few years the study of the composition and behavior of Eucalyptus wood has been mainly focused on E. globulus, the dominant species cultivated in the Iberian Peninsula. Recently, the major features of E. globulus wood macromolecular 
components (Neto et al. 2005) and extractives of this particular species (Silvestre et al. 2005) have been reviewed.

It is known that the amount and composition of wood extractives are important parameters in the wood processing for pulp and paper production (Back and Allen 2000; Hillman 2002). The E. globulus lipophilic extractives fraction, in particular, has been the subject of a significant number of papers (Swan and Akerblom 1967; Santos et al. 1997; Wallis et al. 1997; Gutiérrez et al. 1998, 1999; Gutiérrez and del Río 2001; Freire et al. 2002a, 2004) not only due to its impact on the formation of pitch deposits, giving rise to dark spots in bleached pulp and paper (Manji et al. 2005; Freire et al. 2002b; Gutiérrez et al. 1998), but also because these components might contribute to the consumption of bleaching chemicals (Freire et al. 2005, 2006a; Neto et al. 2004, 2005; Silvestre et al. 2005). These problems can be responsible for reducing levels of production, for increased operating costs and increased incidence of quality defects in the final product (del Río et al. 2000; Gutiérrez et al. 2001; Freire et al. 2002a).

Although the information gathered for E. globulus might be relevant to design strategies to prevent pitch episodes in bleached pulp mills operating with other Eucalyptus species, it is well known that for the Eucalyptus genus there are considerable variations in the chemical composition inter- and intra-species and with geographic location (Bland 1985; Gutíerrez et al. 1999; Freire et al. 2002a). Therefore, when intensive use of other species is to be implemented, it is strongly advisable to carry out detailed studies on its composition and behaviour during pulping and bleaching.

In Brazil, E. urograndis hybrids are one of the main species used for pulp production, representing nowadays the dominant Eucalyptus species planted in Brazil. This Eucalyptus hybrid shows very high forest productivity (in excess of $60 \mathrm{~m}^{3} / \mathrm{Ha} / \mathrm{year}$ ), has a strong disease resistance, presents a high industrial pulping yield, and produces a high quality fiber for paper production (Gomide et al. 2005).

Due to the interest of this species in the Brazilian industrial context, several research programs have been implemented to improve E. urograndis wood quality and productivity (Rezende et al. 1994; Gonçalves et al. 2001; Gomide et al. 2005), involving genetic markers (Caixeta et al. 2003a) and other wood properties, including physical chemical and characteristics, and mechanical resistance (Caixeta et al. 2003b). In this context, the knowledge of the chemical composition of the newly selected plants woods is a fundamental step to understand and optimize their behavior during pulping and bleaching stages.

In this perspective, and within a wider project aiming to study the chemical composition of the selected plants in the pulping and bleaching process, in the present work we report a detailed characterization of lipophilic extractives of four clones of $E$. urograndis. These clones have been selected due to their high wood productivity and high industrial pulp yield (Gomide et al. 2005). Although a study on the chemical composition of lipophilic extractives of Brazilian E. urograndis (among other hardwood species) has been recently published (Freire et al. 2006), the wood samples used were of unspecified origin. This work aims to report the differences in lipophilic extractives composition of for specific clones of $E$. urograndis, from a of genetic selection program aiming to choose the best clones for pulp and paper production in Brazil. 


\section{EXPERIMENTAL}

\section{Samples}

Wood samples of four selected E. urograndis clones (Uga, Ugb, Ugc and Ugd) were obtained from an eight-year old plantation from the state of Bahia in Brazil. The samples were obtained from the whole stem wood, as used in the pulp industry. The wood material was bark-free, chopped into small pieces (industrial size), and air-dried at ambient temperature for five days. It was then ground to pass a $1 \mathrm{~mm}$ sieve, screened in a vibratory sieving apparatus, and the 40-60 mesh fraction was used for chemical analysis.

\section{Extraction}

Air-dried powdered samples $(2.00 \mathrm{~g})$ were extracted with acetone for 6 hours using a Soxhlet apparatus. The solvent was removed under reduced pressure in a rotary evaporator, and the extracts were weighed. All extractions were carried out in triplicate, and the extraction yields were expressed in percentage in relation to the wood's dry weight.

To isolate the lipophilic fraction, the acetone extract was redissolved in dichloromethane $(3 \times 2 \mathrm{~mL})$ and filtered off, as described by del Río et al. (1998). The derivatized dichloromethane soluble (lipophilic) residues were analyzed by GC-MS, before and after hydrolysis as described bellow.

\section{Alkaline Hydrolysis}

$10 \mathrm{mg}$ of the dichloromethane extract were added to a two-neck round-bottomed flask, followed by $1.8 \mathrm{~mL}$ aqueous solution of $\mathrm{KOH}\left(3 \mathrm{~mol} \mathrm{~L}^{-1}\right)$ and $0.2 \mathrm{~mL}$ of methanol. The mixture was refluxed under nitrogen atmosphere for $1 \mathrm{~h}$. It was then cooled down to room temperature, acidified with aqueous $\mathrm{HCl}\left(3 \mathrm{~mol} \mathrm{~L}^{-1}\right)$ to $\mathrm{pH} \sim 2$ and extracted with dichloromethane $(3 \times 2 \mathrm{~mL})$. The combined organic extracts were dried over anhydrous $\mathrm{MgSO}_{4}$, filtered off, and the solvent was completely removed under reduced pressure in a rotary evaporator.

\section{Derivatization}

Aliquots of hydrolyzed and non-hydrolyzed dichloromethane extracts $(2.0 \mathrm{mg})$ were dissolved in pyridine $(60 \mu \mathrm{L})$ in capped vials followed by the addition of $100 \mu \mathrm{L}$ bis(trimethylsilyl)-trifluoroacetamide containing $1 \%$ chlorotrimethylsilane. The reaction mixture was heated at $70{ }^{\circ} \mathrm{C}$ for $30 \mathrm{~min}$. It was then cooled down to room temperature before GC-MS analysis (Cruz et al. 2006).

\section{GC-MS Analysis}

GC-MS analyses were performed on a Shimadzu PQ5050A GC-MS equipped with an AOC-5000 autoinjector and a DB-1 J\&W capillary column ( $30 \mathrm{~m} \times 0.25 \mathrm{~mm}$ i.d., $0.25 \mu \mathrm{m}$ film thickness), using helium as carrier gas $(35 \mathrm{~cm} / \mathrm{s})$. The chromatographic conditions were as follows: injector temperature $290^{\circ} \mathrm{C}$; oven initial temperature $80^{\circ} \mathrm{C}$ held for $5 \mathrm{~min}$; temperature rate $4{ }^{\circ} \mathrm{C} / \mathrm{min}$; final temperature $285^{\circ} \mathrm{C}$ held for $40 \mathrm{~min}$. The 
transfer-line temperature was $290{ }^{\circ} \mathrm{C}$, and a split ratio of 1:10 was used. The mass detector was operated at electron impact mode $(70 \mathrm{eV})$ with a scan range of 30 to $600 \mathrm{~m} / \mathrm{z}$.

For semi-quantitative analysis, the GC-MS equipment was calibrated with pure reference compounds, representative of the major extractives components (namely, hexadecanoic acid, hexadecan-1-ol, 16-hydroxyhexadecanoic acid, 2-hydroxyoctanoic acid, tetracosane, $\beta$-sitosterol and trans-ferulic acid), relative to hexanedioic acid and tetracosane used as internal standards, as described by Freire et al. (2002a). The corresponding response factors needed to obtain correct quantifications were calculated as an average of sixteen GC-MS runs.

Compounds were identified as TMS derivatives by comparing their mass spectra with the GC-MS spectral library (Willey 333.000), with data from the literature and when necessary, by injection of standard compounds.

\section{RESULTS AND DISCUSSION}

The present study has considered the analysis of the nonpolar extracts before and after alkaline hydrolysis to verify the amount of lipophilic compounds present in the woods in free and esterified forms, as has been reported by others (Swan and Akerblom 1967; Santos et al. 1997; Gutiérrez et al. 1999; Freire et al. 2002a, 2004; Silvestre et al. 2005). The lipophilic fraction can be selectively isolated from the more complex acetone extract by dissolution in small volumes of dichloromethane (del Río et al. 1998; Silvério et al. 2006).

The total amount of extractives (3.92\%) from Ugc dry wood was much higher than the values found for the other three clones $(1.32 \% ; 1.92 \%$ and $2.17 \%$ for Uga, Ugb and Ugd, respectively). In terms of the lipophilic fraction, clones Ugd and Ugb presented slightly higher yields $(0.53 \%$ and $0.55 \% \mathrm{w} / \mathrm{w}$, respectively), than those found for Ugc and Uga $(0.44 \%$ and $0.38 \% \mathrm{w} / \mathrm{w}$, respectively).

The average percentage of lipophilic extractives $(0.47 \%)$ found for the studied clones was superior to the typically reported values $(\sim 0.26 \%)$ for E. globulus (Gutiérrez et al. 1998, 1999; Freire et al. 2002a) and also to the values reported for E. urograndis $(0.35 \%)$ and E. grandis $(0.36 \%)$ (Freire et al. 2006b), suggesting that increased attention should be paid to avoid pitch problems while processing wood from these clones for bleached pulp production

Fig. 1 shows a typical GC-MS chromatogram obtained for E. urograndis (Uga) extract, after alkaline hydrolysis. The GC-MS analysis of the derivatized dichloromethane extracts before and after hydrolysis of the four E. urograndis clones (Uga, Ugb, Ugc and Ugd) revealed that they were quite similar in terms of qualitative composition, although from a quantitative point of view the extract of Ugc contained higher amounts of fatty acids and steroids (Table 1).

Fatty acids and sterols are the main groups of compounds found in the lipophilic extractives of the four studied Eucalyptus clones, along with smaller amounts of long chain aliphatic alcohols, hydrocarbons and aromatic compounds. The major classes of identified compounds and their abundances, before and after hydrolysis, are shown in Table 1 and Fig. 2. 


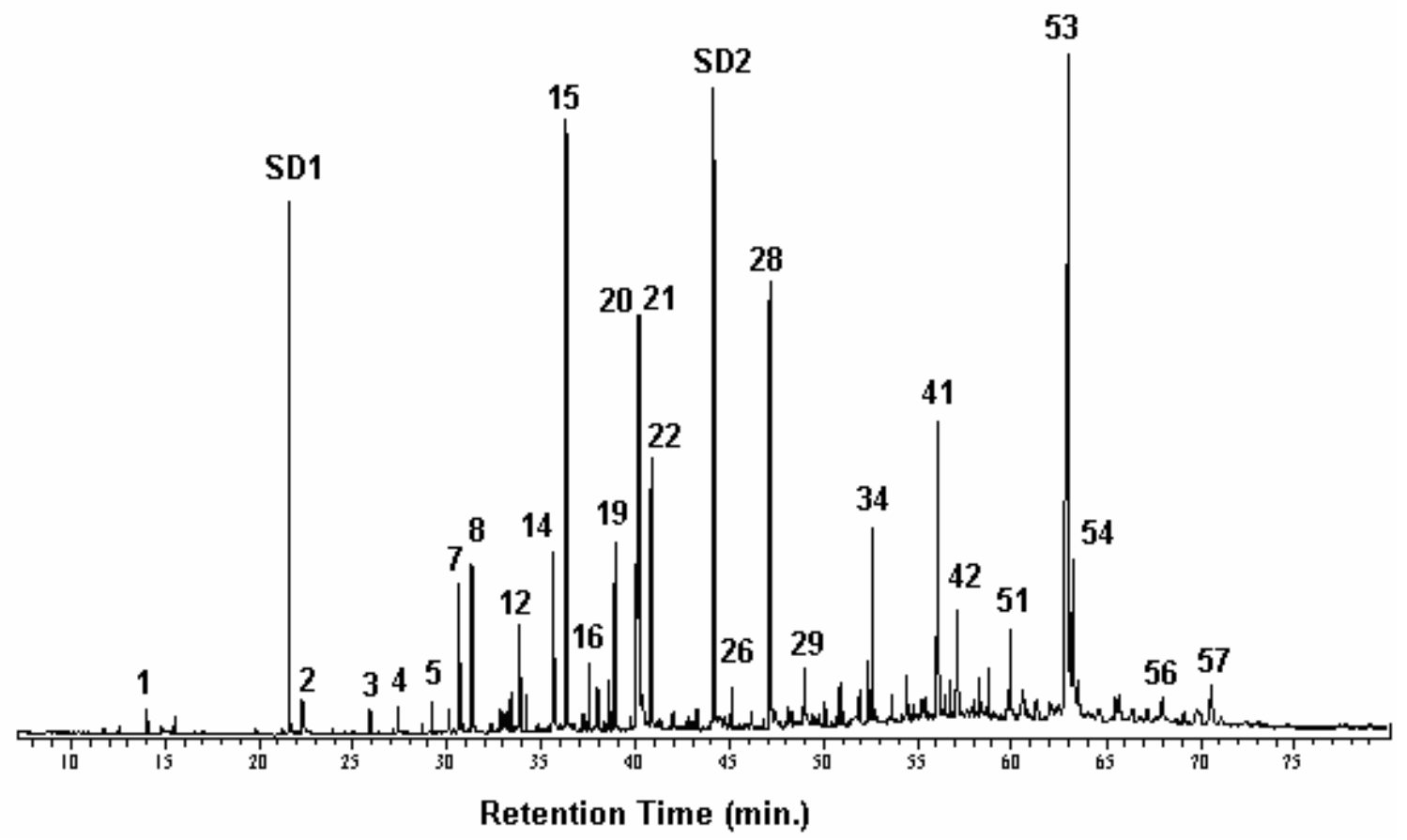

Fig. 1. Total ion chromatogram of the derivatized lipophilic extract of E. urograndis (Uga) wood: IS1 and IS2: internal standards. 1- Glycerol, 2- 3-methoxy-4-hydroxy-benzaldehyde, 3 - Dodecanoic acid, 4- 4-Hydroxy-3,5-dimethoxybenzoic acid, 5- 4-Hydroxy-3-methoxybenzoic acid, 6- Nonanodioic acid (azelaic acid), 7- Tetradecen-9-enoic acid, 8- Tetradecanoic acid, 9- 4-Hydroxy-3,5-dimethoxybenzoic acid, 10- pentadec-9-enoic acid, 11 cis-Ferulic acid, 12- Pentadecanoic acid, 13- Hexadecan-1-ol, 14 - Hexadecan-9-enoic acid, 15 - Hexadecanoic acid, 16 - trans-Ferulic acid, 17- Heptadec-9-enoic acid, 18- Heptadecanoic acid, 19- Octadecan1-ol, 20- Octadec-9,12-dienoic acid, 21- Octadec-9-enoic acid, 22- Octadecanoic acid, 23- Hydrocarbon*, 24- Nonadecanoic acid, 25- Eicosan-1-ol, 26- Eicosanoic acid, 27- Hydrocarbon $^{*}$, 28- Hydrocarbon*, 29- Docosanoic acid, 30- 2-hydroxyhexadecanoic acid, 31- Tricosanoic acid, 32- Tetracosan-1-ol,,33- Hydrocarbon*, 34- Tetracosanoic acid, 35- Hydro- carbon*, 36- Pentacosanoic acid, 37- 2-Hydroxytetracosanoic acid, 38- Hexacosan-1-ol, 39- 22-Hydroxydocosanoic acid, 40- Hydrocarbon*, 41- Hexacosanoic acid, 42- Stigmast-5-en-3-ol, 43- Heptacosanoic acid, 44- Cholest-8-en-3-one, 45- non-identified (n.i.) steroid, 46- n.i. steroid, 47- Cholestane-3,5-diol, 48- n.i. steroid, 49- 24-Hydroxytetracosanoic acid, 50- Octacosan-1-ol, 51- Octacosanoic acid, 52- n.i. steroid, 53- $\beta$-Sitosterol, 54- $\beta$-Sitostanol, 55- 25-Hydroxypentacosanoic acid, 56- 26-Hydroxyhexacosanoic acid, 57- Stigmasta-5,22-dien-3-ol. ${ }^{*}$ The compound was not completely identified as the molecular ion peak was not observed in the mass spectrum, but from the fragmentation pattern it was clearly a long chain hydrocarbon.

Although the percentage of lipophilic extractives from the wood of the four clones of E. urograndis varied within a narrow range $(0.38 \%$ to $0.55 \% \mathrm{w} / \mathrm{w})$, a striking variation in the amounts of specific lipophilic compounds identified was verified by GCMS. This significant variation is mainly due to fatty acids and sterols, as can be observed in Table 1. After alkaline hydrolysis, a substantial increase in the amount of both fatty acids and steroids was observed, as detected by GC-MS analysis (Table 1, Fig. 2). These results provide evidence of the presence of significant amounts of esterified structures, 
such as sterols esters and other esters in the original extract, as reported in other studies (Wallis and Wearne 1997; Gutierrez et al. 1999; Freire et al. 2002a, 2002b).

The increase in the percentage of fatty acids after hydrolysis is due essentially to components containing 16 to 18 carbons atoms and others having 19 or more carbons atoms (Fig. 3), including saturated and unsaturated fatty acids and hydroxyacids. In accordance with our results, there have been reports of the association of these acids with sterols, alcohols, or glycerol (Gutierrez et al. 1999; Freire et al. 2002a).

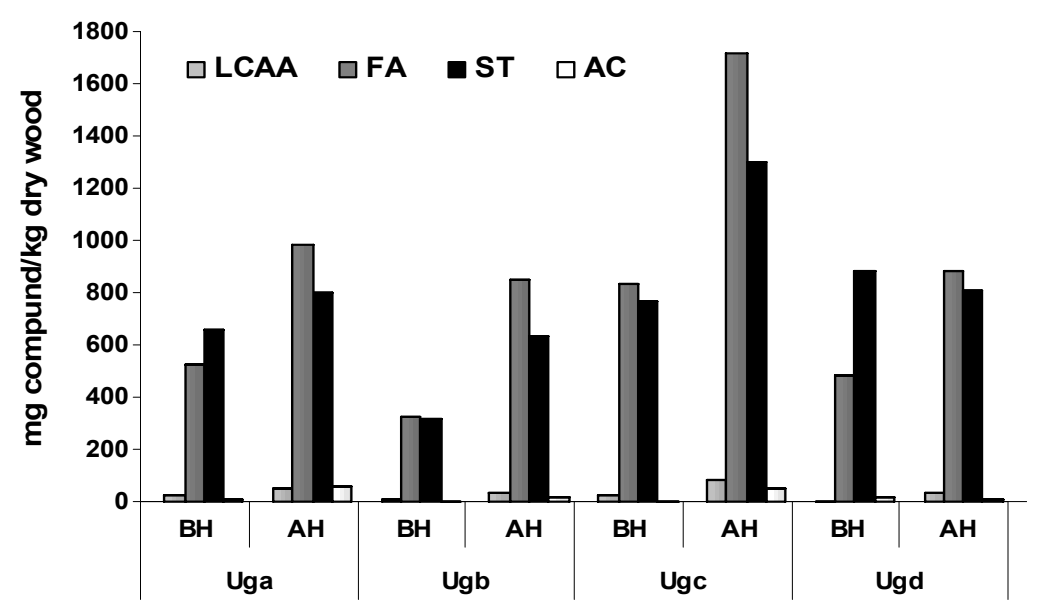

Fig. 2. Major families of compounds identified in the lipophilic extracts, before (BH) and after hydrolysis $(\mathbf{A H})$, of $E$. urograndis clones (Uga, Ugb, Ugc and Ugd, respectively). LCAA: long chain aliphatic alcohols, FA: fatty acids, ST: sterols, AC: aromatic compounds.

The most abundant fatty acids found in the hydrolyzed and non-hydrolyzed dichloromethane extracts were palmitic, linoleic, and oleic acids. For the hydrolyzed extracts the amounts found were: palmitic $(161.4,162.7,310.8$ and $166.9 \mathrm{mg} / \mathrm{kg}$ for Uga, $\mathrm{Ugb}, \mathrm{Ugc}$ and Ugd, respectively), linoleic (172.6, 78.6, 257.1 and $147 \mathrm{mg} / \mathrm{kg}$ for Uga, $\mathrm{Ugb}, \mathrm{Ugc}$ and Ugd, respectively), and oleic (145.8, $127.2,305.4$ and $105.7 \mathrm{mg} / \mathrm{kg}$ for Uga, Ugb, Ugc and Ugd, respectively). Compared to previously published data, these figures are much higher than those reported in the hydrolyzed extracts of E. globulus (76.1 mg/kg of palmitic acid, $62.8 \mathrm{mg} / \mathrm{kg}$ of linoleic acid and $41.0 \mathrm{mg} / \mathrm{kg}$ of oleic acid) (Freire et al. 2002a).

Other identified fatty acids were dodecanoic, tetradecanoic, pentadecanoic, hexadecanoic, heptadecanoic, octadecanoic, eicosanoic, docosanoic, tricosanoic, tetracosanoic, pentacosanoic, hexacosanoic, heptacosanoic, and octacosanoic acids.

The total amount of fatty acids found in the hydrolyzed dichloromethane extracts for clones Uga, Ugb, Ugc, and Ugd were significantly higher (979.5, 841.5, 1930.3 and $886.0 \mathrm{mg} / \mathrm{kg}$ ) when compared to the amount found in the dichloromethane extract of $E$. globulus $(520.9 \mathrm{mg} / \mathrm{kg}$ ) (Freire et al. 2002a). The same was observed for the nonhydrolyzed dichloromethane extract. These results suggest that all four E. urograndis clones studied are more prone to result in pitch deposition during pulp production, but 
particularly the Ugc clone, when compared with E. globulus. Fatty acids were identified based on their characteristic fragmentation patterns (Budzikiowicz and Djerassi 1967; McLafferty and Turecek 1992; Freire et al. 2002a).

Table 1 - Main families of lipophilic components identified in the lipophilic extracts of woods of the $E$. urograndis clones and their contents $(\mathrm{mg} / \mathrm{kg}$ dry wood) before $(\mathrm{BH})$ and after $(\mathrm{AH})$ alkaline hydrolysis.

\begin{tabular}{lcccccccc}
\hline \multirow{2}{*}{ Family } & \multicolumn{2}{c}{ UGA } & \multicolumn{2}{c}{ UGB } & \multicolumn{2}{c}{$\mathrm{UGC}$} & \multicolumn{2}{c}{ UGD } \\
& $\mathrm{BH}$ & $\mathrm{AH}$ & $\mathrm{BH}$ & $\mathrm{AH}$ & $\mathrm{BH}$ & $\mathrm{AH}$ & $\mathrm{BH}$ & $\mathrm{AH}$ \\
\hline Fatty acids & $\mathbf{5 2 0 . 3}$ & $\mathbf{9 7 9 . 5}$ & $\mathbf{3 2 8 . 3}$ & $\mathbf{8 4 1 . 5}$ & $\mathbf{8 3 9 . 6}$ & $\mathbf{1 9 3 0 . 3}$ & $\mathbf{4 8 5 . 9}$ & $\mathbf{8 8 6 . 0}$ \\
Saturated & 305.1 & 516.5 & 176.9 & 569.2 & 416.3 & 1030.2 & 277.0 & 533.4 \\
Unsaturated & 209.5 & 405.9 & 144.6 & 240.2 & 420.5 & 832.9 & 195.6 & 329.1 \\
Hydroxyacids & 5.7 & 57.0 & 6.8 & 32.1 & 2.8 & 67.2 & 13.3 & 23.6 \\
\hline Aromatic compounds & $\mathbf{8 . 9}$ & $\mathbf{5 9 . 4}$ & - & $\mathbf{1 5 . 2}$ & - & $\mathbf{4 6 . 9}$ & $\mathbf{1 4 . 5}$ & $\mathbf{7 . 7}$ \\
Aromatic acids & 8.9 & 49.7 & - & 15.2 & - & 46.9 & 6.8 & 11.9 \\
Others & - & 9.7 & - & - & - & - & - & - \\
\hline Long Chain Aliphatic & $\mathbf{2 2 . 6}$ & $\mathbf{4 8 . 8}$ & $\mathbf{8 . 1}$ & $\mathbf{3 2 . 4}$ & $\mathbf{2 4 . 8}$ & $\mathbf{8 1 . 7}$ & $\mathbf{2 . 8}$ & $\mathbf{2 9 . 5}$ \\
Alcohols & 18.3 & 45.6 & 8.1 & 22.1 & 21.8 & 42.8 & 2.8 & 29.5 \\
$<$ C20 & 4.3 & 3.2 & - & 10.3 & 3.0 & 38.9 & - & - \\
$>$ C20 & $\mathbf{6 0 4 . 1}$ & $\mathbf{7 8 1 . 4}$ & $\mathbf{3 1 4 . 7}$ & $\mathbf{6 2 1 . 3}$ & $\mathbf{7 6 8 . 4}$ & $\mathbf{1 2 3 9 . 8}$ & $\mathbf{8 8 4}$ & $\mathbf{8 0 9 . 8}$ \\
\hline Sterols & $\mathbf{6 7 . 8}$ & $\mathbf{2 7 . 7}$ & $\mathbf{1 1 9 . 2}$ & $\mathbf{1 8 . 4}$ & $\mathbf{1 8 . 6}$ & $\mathbf{8 . 3}$ & $\mathbf{1 5 . 0}$ & $\mathbf{1 4 . 2}$ \\
\hline Hydrocarbons & 52.4 & 19.0 & 3.5 & 13.5 & - & 60.5 & - & - \\
\hline Others/unidentified & $\mathbf{1 2 7 6 . 1}$ & $\mathbf{1 9 1 5 . 8}$ & $\mathbf{7 7 3 . 8}$ & $\mathbf{1 5 4 2 . 3}$ & $\mathbf{1 6 4 1 . 4}$ & $\mathbf{3 3 7 7 . 9}$ & $\mathbf{1 3 8 8 . 7}$ & $\mathbf{1 7 5 1 . 4}$ \\
\hline TOTAL & & & & & & & & \\
\hline
\end{tabular}

GC-MS analysis also made it possible to identify four $\omega$-hydroxy fatty acids, namely 22-hydroxydocosanoic, 24-hydroxytetracosanoic, 25-hydroxypentacosanoic, and 26-hydroxyhexacosanoic acids. These $\omega$-hydroxy fatty acids were identified as TMS derivatives, based on their characteristic fragmentations (Draffan et al. 1968; Petersson 1972; Freire et al. 2002a), and the fragmentations confirmed by injection of a reference sample of 16-hydroxyhexadecanoic acid (as TMS derivative).

Two $\alpha$-hydroxyfatty acids, namely 2-hydroxytetracosanoic and 2-hydroxyhexadecanoic acid were found in E. urograndis wood extracts after alkaline hydrolysis, based on their characteristic fragmentation patterns (Budzikiewicz et al. 1967; Draffan et al. 1968; Petersson 1972; McLafferty and Turecedk 1992; Freire et al. 2002a), and the fragmentations confirmed by injection of compounds. The presence of $\alpha$-hydroxyfatty acids has been previously reported in E. globulus (Freire et al. 2002a, 2002b).

It has been demonstrated that these $\alpha$ - and $\omega$-hydroxyfatty acids are commonly found as abundant components of pitch deposits (Silvestre et al. 1999; Freire et al. $2002 b$ ). The significantly lower abundance of $\alpha$ - and $\omega$-hydroxy fatty acids in the wood 
of the E. urograndis clones studied seems to be clearly beneficial as far as pitch formation is concerned.

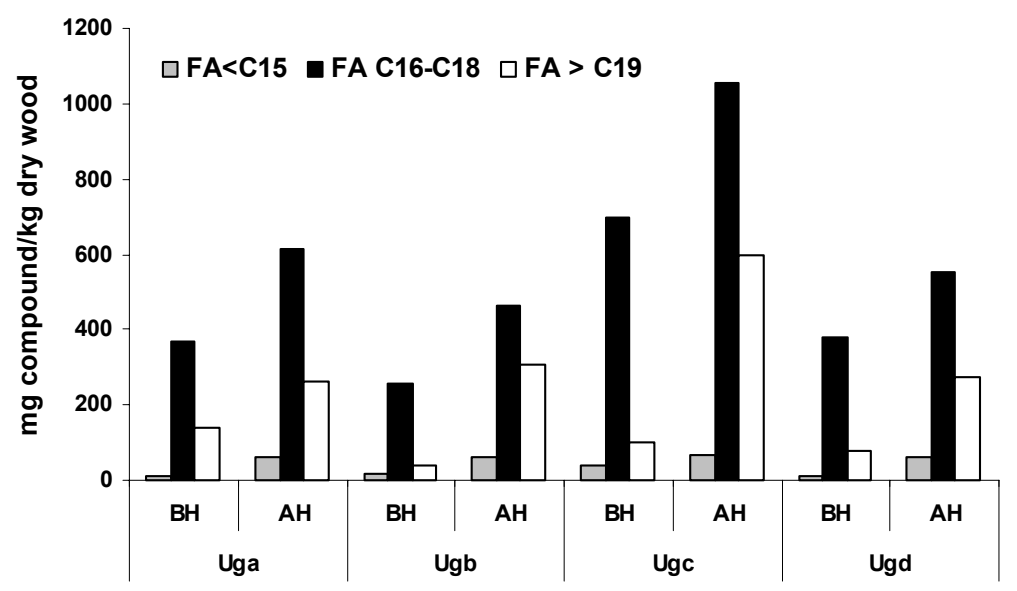

Fig. 3. Major fatty acids present in the lipophilic extracts of the clones of $E$. urograndis (Uga, Ugb, Ugc and Ugd) investigated before (BH), and after hydrolysis (AH), FA <C15 fatty acids with less than 16 carbon atoms, FA C16-C18 carbons atoms and FA > 19 fatty acids with more than 19 carbons atoms.

In terms of total sterols content (Fig. 2; Table 1), it was observed that the hydrolysis caused an increase for all clones except Ugd, where it stayed roughly constant. These results indicate that the wood steroids are in both free and esterified forms. Among the steroids identified in all extracts, $\beta$-sitosterol and $\beta$-sitostanol were the main ones. In the hydrolyzed extracts, the amount of $\beta$-sitosterol for clone Ugb $(429.9 \mathrm{mg} / \mathrm{kg})$ was slightly higher than has been reported for E. globulus $(346.7 \mathrm{mg} / \mathrm{kg}$ ) (Freire et al. 2002a), while the quantities found in Uga $(608.3 \mathrm{mg} / \mathrm{kg}), \mathrm{Ugc}(907.0 \mathrm{mg} / \mathrm{kg})$ and Ugd $(708.4$ $\mathrm{mg} / \mathrm{kg}$ ) were significantly higher. These compounds are quite common in Eucalyptus wood extracts, and their presence has been reported in pitch deposits (Freire et al. 2002b; Silvestre et al. 1999).

Other steroids, identified in smaller amounts, were stigmast-5-en-3-ol (Ugc and Ugd, after hydrolysis), cholest-8-en-3-one (Ugb, after hydrolysis), cholestane-3,5-diol (after hydrolysis), stigmaste-5,22-dien-3-ol (Uga, before and after hydrolysis), and stigmasta-4-en-3-one (Uga, before and after hydrolysis, Ugd, before hydrolysis). These compounds were identified based in their fragmentation characteristics (Budzikiewicz et al. 1967; Diekman and Djerassi 1967; Gustafsson et al. 1968; Brooks et al. 1979).

It is worth mentioning that the total amounts of the two most abundant families (after hydrolysis), i.e. fatty acids and sterols found in the four clones, is higher than the values previously reported for E urograndis (Freire et al. 2006), which clearly suggests that despite the higher quality of their woods for pulp production, there is an increased potential of pitch formation problems. This potential is particularly acute in the case of Ugc wood. 
Fatty alcohols represented a small portion of the total extractives analyzed by GCMS before and after hydrolysis (Table 1 and Fig. 2). Octadecan-1-ol and hexadecan-1-ol were the major components of this class, followed by eicosan-1-ol, tetracosan-1-ol, hexacosan-1-ol, and octacosan-1-ol. The compounds were identified based on their fragmentation characteristics (Budzikiewicz et al. 1967).

The aromatic fraction was mainly composed by 4-hydroxy-3-methoxy-benzaldehyde, 4-hydroxy-3,5-dimethoxybenzaldehyde, 4-hydroxy-3-methoxybenzoic, and 4hydroxy-3,5-dimethoxybenzoic acids identified in the extracts in small amounts before $(<15 \mathrm{mg} / \mathrm{kg})$ and after $(<60 \mathrm{mg} / \mathrm{kg})$ hydrolysis. Ferulic acid (cis + trans $)$ was found only in the hydrolyzed extracts; it represented the main aromatic compound identified in the extracts of clones Uga, Ugb, Ugc and Ugd (33.3, 8.9, 46.9 and $11.9 \mathrm{mg} / \mathrm{kg}$, respectively).

The percentage of components identified in the hydrolyzed extracts of the clone Uga was approximately $50.5 \%$ of the total lipophilic extractives. These results are in good agreement with other reports in the literature for E. globulus, where only around $50 \%$ of the total mass of the extracts were identified (Freire et al. 2002a, 2002b, 2006b). However, for clones Ugb and Ugd the components identified represented only $28.2 \%$ and $33.1 \%$, respectively, and for clone Ugc approximately $76.8 \%$ of the extractive compounds were identified in agreement with Gutierrez et al. (1999).

This considerable variability the total amounts of identified lipophilic extractives as well as the percentage of the lipophilic extract, is certainly due to the genetic variability between the four clones, together with the variation of growth location (Freire et al. 2006). These differences can be explained by the presence of steryl glycosides, not detected in this work. Steryl glycosides are compounds that do not hydrolyze easily under alkaline hydrolysis conditions, and consequently, may not be identified with the methodology used. These compounds have been reported in several Eucalyptus species (including E. globulus, E. grandis, and E. urograndis) as problematic for pitch deposition (Gutiérrez and del Río 2001; Freire et al. 2004, 2006b).

\section{CONCLUSIONS}

1. The present study reports the identification and quantification of fifty-five compounds present in the lipophilic extracts of four clones of Eucalyptus urograndis.

2. Fatty acids and sterols are responsible, respectively, for approximately $51 \%$ and $41.8 \%$ of the identified compounds in the extracts of the Uga, 54.5\% and $41.2 \%$ of the Ugb, $57.1 \%$ and $38.5 \%$ of the Ugc, and $50.6 \%$ and $46.2 \%$ of the Ugd.

3. The main components of these two classes are palmitoleic, linoleic, and oleic acids, and $\beta$-sitosterol. In general the detected amounts of the components of both families increase considerably after alkaline hydrolysis, which suggest that they could in part be removed in the black liquor, during kraft pulping

4. Three of the studied clones (Uga, Ugb and Ugd) showed identifiable lipophilic extractives in amounts similar to those previously reported for E. urograndis (Freire et al. 2006b), whereas the other clone, Ugc, showed considerably higher amounts. In this perspective, and considering that these figures are in any case considerably 
higher than those reported for Iberian E. globulus, the industrial processing of these clones of wood will require increased attention to the control of pitch formation.

5. Finally, future work will be required to explain the differences in the composition of the lipophilic fraction of the studied clones; and to study the steryl glucosides fraction, known to contribute to pitch deposition (Gutiérrez and del Río 2001; Freire et al. 2004, 2006b).

\section{ACKNOWLEDGMENTS}

The authors are grateful to Conselho Nacional de Desenvolvimento Científico e Tecnológico $(\mathrm{CNPq})$ for financial support and research fellowships (LCAB, DPV) and a PhD studentship (FOS); Fundação de Amparo à Pesquisa do Estado de Minas Gerais (FAPEMIG) for financial support (Research grant $n^{\circ}$ CEX 81796-05).

\section{REFERENCES CITED}

Back, E. L. and Allen, L. H. (eds.) (2000). Pitch Control, Wood Resin and Deresination, Tappi Press, Atlanta.

Bland, D. E. (1985). "The composition and analysis of eucalypt wood," Appita J. 38(4), 291-294.

Brooks, C. J. W. (1979). "Some aspects of mass spectrometry in research on steroids," Phil. Trans. R. Soc. London A, 293, 53-67.

Budzikiewicz, H., Djerassi, C., and Williams, D. H. (1967). Mass Spectrometry of Organic Compounds, Holden-Day, London.

Caixeta, R. P., Carvalho, D., Rosado, S. C. S., and Trugilho, P. F. (2003a). "Variações genéticas em populações de Eucalyptus ssp. detectadas por meio de marcadores moleculares," R. Árvore 27(3), 357-363.

Caixeta, R. P., Trugilho, P. F., Rosado, S. C. S., and Lima, J. T. (2003b). "Propriedades e classificação da madeira aplicadas à seleção de genótipos de Eucalyptus," R. Árvore 27(1), 43-51.

Cruz, M. P., Barbosa, L. C. A., Maltha, C. R. A., Gomide, J. L., and Milanês, A. F. (2006). "Chemical characterization of pitch in Eucalyptus pulp and paper industry." Química Nova 29(3), 459-466.

Del Río, J. C., A. Gutiérrez, F. C., González-Vila, F. J., Martin, F., and Romero, J. (1998). "Characterization of organic deposits produced in kraft pulping of Eucalyptus globulus wood," J. Chromaotgr. A. 823, 457-465.

Del Río, J. C., Romero, J., and Gutiérrez, A. (2000). "Analysis of pitch deposits produced in kraft pulp mills using a totally chlorine free bleaching sequence," J. Chromaotgr. A. 874(2), 235-245.

Diekman, J., and Djerassi, C. (1967). "Mass spectrometry in structural and stereochemical problems. CXXV. Mass spectrometry of some steroid trimethylsilyl ethers," J. Org. Chem. 32, 1005-1012. 
Draffan, G. H., Stillwell, R. N., and McCloskey, J. A. (1968). "Electron impact-induced rearrangement of trimethylsilyl groups in long chain compounds," Org. Mass. Spectr. 1, 669-685.

Freire, C. S. R., Silvestre, A. J. D., and Neto, C. P. (2002a). "Identification of new hydroxy fatty acids and ferulic acid ester in the wood of Eucalyptus globulus," Holzforshung 56(2), 143-149.

Freire, C. S. R., Silvestre, A. J. D., Pereira, C. C. L., Neto, C. P., and Cavaleiro, J. A. S. (2002b). "New lipophilic components of pitch deposits from an Eucalyptus globulus ECF bleached kraft pulp mill," J. Wood Chem. Technol. 22(1), 55-66.

Freire, C. S. R., Silvestre, A. J. D., Neto, C. P., Domingues, P., and Silva, A. M. S. (2004). "New glycosides in the wood and bark of Eucalyptus and Kraft pulps," Holzforshung 58(5), 501-503.

Freire, C. S. R., Silvestre, A. J. D., and Neto, C. P. (2005). "Lipophilic extractives in Eucalyptus globulus kraft pulps. Behaviour during ECF bleaching," J. Wood Chem. Technol. 25(1-2), 67-80.

Freire, C. S. R., Silvestre, A. J. D., Neto, C. P., and Evtuguin, D. V. (2006a). "Effect of oxygen, ozone and hydrogen peroxide bleaching stages on the contents and composition of extractives of Eucalyptus globulus kraft pulps," Biores. Technol. 97(3), 420-428.

Freire, C. S. R., Pinto, P. C. R., Santiago, A. S., Silvestre, A. J. D., Evtuguin, D. V., and Neto, C. P. (2006b). "Comparative study of lipophilic extractives of hardwoods and corresponding ECF bleached Kraft pulps," BioResources 1(1), 3-17.

Gonçalves, F. M. A., Rezende, G. D. S. P., Bertolucci, F. L. G., and Ramalho, M. A. P. (2001). "Progresso genético por meio da seleção de clones de eucalipto em plantios comerciais," R. Árvore 25(3), 295-301.

Gustafsson, J. A., Ryhage, R., and Sjövall. J. (1969). "Migration of the trimethylsilyl group upon electron impact in steroids," J. Am. Chem. Soc. 91(5), 1236-1234.

Gutiérrez, A., Del Río, J. C., Gonzáles-Vila, F. J., and Martin, E. F. (1998). “Analysis of lipophilic extractives from wood and pitch deposits by solid-phase extraction and gas chromatography," J. Chromatogr. A 823, 449-455.

Gutiérrez, A., Del Río, J. C., Gonzáles-Vila, F. J., Martin, E. F. (1999). “Chemical composition of lipophilic extractives from Eucalyptus globulus Labill wood," Holzforschung 53, 481-486.

Gutiérrez, A., Romero, J., and del Río, J. C. (2001). "Lipophilic extractives from Eucalyptus globulus pulp during kraft cooking followed by TCF and ECF bleaching," Holzforschung 55(3), 260-264.

Gutiérrez, A., and del Río, J. C. (2001). “Gas chromatography-mass spectrometry demonstration of steryl glycosides in eucalypt wood kraft pulp and process liquids,"Rapid Commun. Mass Spectrom. 15, 2515-2520.

Hillman, D. C. (2002). "Single-species pulping. The world's preferred market pulps," Solutions, Nov., 27-28.

Manji, A., Salgar. S., Constant, J., Silva, D. J. S., and Almeida, J. M. (2005). "Uma nova alternativa para eliminar o talco e reduzir pitch e extrativos na produção de celulose," O Papel, Maio, 82-87. 
McLafferty, F. W., and Turecek, F. (1992). Interpretation of Mass Spectra, $4^{\text {th }}$ Ed., University Science, Books, California.

Neto, C. P., Silvestre, A. J. D., Evtuguin, D. V., Freire, C. S. R., Pinto, P. C. R., and Santiago, A. S. (2004). "Bulk and surface composition of ECF bleached hardwood kraft pulp fibres," Nord Pulp Paper Res. J. 19(4), 513-520.

Neto, C. P., Evtuguin, D. V., and Pinto, P. C. (2005). "Componentes macromoleculares das madeiras de Eucalyptus e de outras folhosas: na aptidão ao cozimento e branqueamento," O Papel/Aveiro 1, 17-26.

Petersson, G. (1972). "Mass spectrometry of hydroxyl dicarboxylic acids as trimethylsilyl derivatives. Rearrangement fragmentations," Org. Mass Spec. 6, 565-576.

Rezende, G. D. S. P., Bertolucci, F. L. G., and Ramalho, M. A. P. (1994). "Eficiência da seleção precoce na recomendação de clones de eucalipto avaliados no norte do Espírito Santo e sul da Bahia," Revista Cerne 1(1), 45-50.

Santos, G. G., Alves, J. C. N., Rodilla, J. M. L., Duarte, A. P., Lithgow, A. M., and Urones, J. G. (1997). "Terpenoids and other constituints of Eucalyptus globulus," Phytochem. 44(7), 1309-1312.

Shatalov, A. A., Evtuguin, D. V., and Pascoal Neto, C. (1999). "2-O- $\alpha-D-$ Galactopyranosyl-4-O-methyl- $\alpha$-D-glucurono)-D-Xylan from Eucalyptus globulus Labill," Carbohydr. Res. 320, 93-99.

Silvério, F. O., Barbosa, L. C. A., Gomide, J. L., Reis, F. P., and Pilo-Veloso, D. (2006). "Metodologia de Extração e Determinação do Teor de Extrativos em Madeiras de Eucalipto," R. Árvore 62(6), 1009-1016.

Silvestre, A. J. D., Pereira, C. C. L., Neto, C. P., Evtuguin, D. V., Duarte, A. C., Cavaleiro, J. A. S., and Furtado, F. P. (1999). "Chemical composition of pitch deposits from an ECF Eucalyptus globulus bleached kraft pulp mill: Its relationship with wood extractives and additives in process streams," Appita J. 52(5), 375-382.

Silvestre, A. J. D., Neto, C. P., and Freire, C. S. R. (2005). "Componentes lipofílicos da madeira de Eucalyptus globulus: Comportamento durante a produção de pasta de papel," O Papel/Aveiro 1, 5-16.

Swan, B., and Akerblom, I. S. (1967). "Wood extractives from Eucalyptus globulus Labill," Svensk Papperstidn 70(7), 239-244.

Wallis, A. F. A., Wearne, R. H., and Wright, J. P. (1997). “Analysis of resin in eucalypt woods and pulps," Proc. $51^{\text {st }}$ Annual General Conference. Appita, Melbourne, Vol. I, pp. 45-50.

Wallis, A. F. A., Wearne, R. H., and Wright, J. P., (1999). “Analysis of resin in eucalypt woods and pulps," Appita J. 52(4), 295-299.

Article submitted: Jan. 18, 2007; First reviews completed: Feb. 13, 2007; Revised version accepted: Feb. 24, 2007; Published: Feb. 27, 2007. 